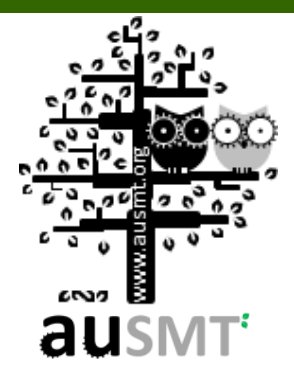

\title{
Ontology-based Patent Licensing and Litigation Strategic Knowledge System for the Light Emitting Diode Industry
}

\author{
Amy J.C. Trappey ${ }^{1}$, Yu-Hui Wang'2, Charles V. Trappey ${ }^{3}$, \\ Chun-Yi Wu ${ }^{1}{ }^{*}$, and Tzu-Hsuan Lin ${ }^{2}$ \\ ${ }^{1}$ Department of Industrial Engineering and Engineering Management, National Tsing Hua University, Taiwan \\ ${ }^{2}$ The Institute of Service and Technology Management, National Taipei University of Technology, Taiwan \\ ${ }^{3}$ Department of Management Science, National Chiao Tung University, Taiwan \\ (Received 21 November 2012; Accepted 18 January 2013; Published on line 1 September 2013) \\ *Corresponding author: d9534524@oz.nthu.edu.tw \\ DOI: 10.5875 /ausmt.v3i3.180
}

\begin{abstract}
This research studies the patents, intellectual properties and licensing landscape of the Light Emitting Diode (LED) industry. The ontology of LED technology is described and defined as four major sub-technology domains. The finding provides LED companies with consistent knowledge of their own and their competitors' patents and intellectual property rights (IPR) ownership. Major LED companies often use their IPRs to gain and protect their market competitiveness, to form alliances, and to create patent licensing or cross-licensing strategies. Newly established LED technology companies competing with global industry leaders face many challenges unaddressed in the research literature. This research focuses on the empirical and quantitative analysis of historical IP and patent related conduct in relation to corporate strategy. Based on the heuristic rules derived from historical conduct, the research establishes a standardized analytical procedure to use in the evaluation of patent licensing and litigation. The results help researchers effectively and consistently analyze their technical capabilities, evaluate their patent licensing strategies, and review litigation in view of the LED-related IP and patent marketplace.
\end{abstract}

Keywords: Light Emitting Diode (LED); patent intelligence; intellectual property rights (IPR); patent licensing; IP market strategy

\section{Introduction}

The growth of global regulations, consumer interest groups, industrial associations, and authorities in environmental preservation are impacting the way enterprises view their research and development. There has been a significant increase in green product technology development, production and, subsequently, application and adoption. One of these technological developments is the light emitting diode (LED). A light emitting diode has many advantages, such as small size, long lifespan, low electricity consumption, and minimal pollution (e.g., $\mathrm{CO}_{2}$ emission and landfill disposal). Forecasting substantial market growth, many enterprises have invested substantially in LED R\&D, have increased production, and have built new supply chains to boost LED commercialization. Patents are a critical means for LED companies to create and protect intellectual property rights (IPRs) and market share. Industry data shows that from 1996 to 2010, 168 LED patent infringement lawsuits occurred worldwide. Most of these LED lawsuits were filed by the five leading LED companies [1]. To solve patent litigation disputes, patent licensing has been one of the leading impetuses for international technology transfer [2].

This research investigates the litigation and licensing practices of major LED companies which have been granted patents by the United States Patent and Trademark Office (www.uspto.gov). First, text mining is 
used to extract key phrases from the US patents involved in the litigation and licensing cases (2002 2011). Afterward, these key phrases and their relationships form the elements of the LED domain ontology. Using the ontology to search and classify LED related patents allows companies to identify their capability in certain technical sub-domains and to improve their patent portfolio. A matrix of historical IP conduct is used to investigate patterns in licensing, cross-licensing or litigation for the major LED companies. Based on the IP conduct matrix, this research defines a standardized process and incorporates heuristic knowledge rules to derive licensing and litigation strategies and competitive market actions. The framework of the knowledge system was verified and refined by LED technical experts and IPR managers knowledgeable about current applications.

\section{Background and Literature Review}

The literature of this research is divided into three themes. The first part is the investigation of patent litigation and licensing with a particular focus on damage remedies and royalties. The second part is the literature

Amy J.C. Trappey is a Tsing Hua Distinguished Professor in the Department of Industrial Engineering and Engineering Management (IEEM), National Tsing Hua University (NTHU), Taiwan. She received her Ph.D. in industrial engineering from Purdue University (USA). She has taught at lowa State University and was a visiting professor and research fellow at George Mason University (USA) and Queensland University of Technology (Australia). Prof. Trappey has also served as the Dean for the College of Management at National Taipei University of Technology $(2008$ 2011). Her research interests are in e-business, e-automation, knowledge engineering, patent analysis, and intellectual property management. Dr. Trappey is an ASME and ISEAM Fellow.

Yu-Hui Wang is an assistant professor at National Taipei University of Technology (NTUT), Taipei. She received her M.S. and Ph.D. degrees in Law from the National Chengchi University (NCCU) Taipei, Taiwan. Dr. Wang works cooperatively with faculties and researchers on many Intellectual Property Management projects. Dr. Wang currently serves as the editor for both the Journal of Communications and Information Sciences (JCIS) and Advances in Multimedia Technology (AMT). She also serves as the co-director of the Intellectual Property and Industry Analysis Platform for NTUT.

Charles V. Trappey is a professor of marketing in the Department of Management Science at the National Chiao Tung University (NCTU), Taiwan. He has served as Associate Dean for the College of Management at NCTU. Prof. Charles Trappey received his Ph.D. degree in Consumer Science and Retailing from Purdue University, USA. He has taught at Purdue University and was a visiting professor and research fellow at George Mason University and Queensland University of Technology. His research interests are in technology marketing, technology forecasting, and service innovation.

Chun-Yi $\mathbf{W u}$ is a post-doctoral researcher in the Enterprise Logistic and E-Business Center (ELEBC) and the Department of Industrial Engineering and Engineering Management at NTHU, Taiwan. He has served as a senior consultant for Wheeljet, Inc. in system analysis and software development. His research interests include the development of computerized intelligent systems and knowledge management of patents and IP using data and text mining methodology.

Tzu-Hsuan Lin received her M.S. degree from the Department of Industrial Engineering and Management at NTUT in 2012 related to descriptions of ontology and methodological construction. In the last sub-section, we define and review patent quality evaluation approaches.

\section{Patent litigation and licensing}

A patent is a type of intellectual property right (IPR) granted by a government to the owner(s) of the invention. [3] reports that data provided by patents have advantages since they contain information relating to the population of innovating firms, are accessible and catalogued in the same time period, are stored for a long period of time, and are continuously updated in a standardized format. Patents provide rights, such as twenty-year protection, and allow others to search prior arts and to examine the novel and inventive steps which, if not published, would not be obvious and would be difficult to protect against illegal industrial and commercial applications [4]. Patents exclude others from using the invention without the patent owner's consent. A patent owner can grant rights to others (licensees) to utilize the technical knowledge for commercial purposes. [5] note that patent licensing between companies leads to standardized product specifications. The forms of patent licensing agreements include exclusive licensing, non-exclusive licensing, cross-licensing, patent pools, and strategic licensing. An exclusive license means that the licensor provides the licensee a promise which gives the licensee the sole IPR and excludes the licensor from granting the IPR to any other party. A non-exclusive licensing agreement means that the licensor is allowed to grant licenses to several licensees simultaneously. A cross licensing agreement allows two or more parties to grant licenses to each other for the exploitation of the subject matter claimed in one or more of the patents that each party owns. A patent pool is an agreement among patent owners to license a set of patents owned by the group to third parties. Strategic licensing means a patent holder will consider the nature of the company as well as the particular property before deciding on any license agreement.

[6] propose an approach for creating and utilizing keyword based patent maps to analyze technology creation and activity to help people discover new patenting opportunities. Table 1 shows the patent licenses between five leading LED companies. Philips, a historical leader in the LED industry with more than 4,000 patents listed in the USPTO database, plays an important role in developing advanced technologies for Light Emitting Diodes (LED). This company and the other key players have organized competitive and sustainable patent licensing strategies [7]. 
Table 1. Patent licensing for five leading LED companies

\begin{tabular}{|c|c|c|}
\hline Time & Licensing Companies & Licensing Information \\
\hline 2002.09 & Nichia $\rightarrow$ Toyoda Gosei & White LEDs which use YAG phosphor material \\
\hline 2005.07 & Toyoda Gosei $\rightarrow$ Dominant Semi & White LEDs which use ortho-silicate phosphors \\
\hline 2005.09 & OSRAM $\rightarrow$ Yahsin & White LED licensing \\
\hline 2006.04 & Toyoda Gosei $\leftrightarrow$ Philip Lumileds Lighting & Red LED and blue LED cross-licensing \\
\hline 2006.08 & ITRI $\rightarrow$ Epistar & Red LED and blue LED licensing \\
\hline 2007.10 & Osram $\rightarrow$ Toyoda Gosei & $\begin{array}{l}\text { Indium gallium nitride (InGaN) semiconductor } \\
\text { technologies that form the basis for laser diodes and LEDs } \\
\text { in white, blue and green. }\end{array}$ \\
\hline 2008.05 & Cree $\rightarrow$ Toyoda Gosei & LED chips and white LED licensing \\
\hline 2009.12 & Toyoda Gosei $\rightarrow$ Sharp & LED chips with nitride-based and HR LED licensing \\
\hline 2010.09 & Toyoda Gosei $\rightarrow$ Epistar & InGaN-based and AlGalnP-based LED licensing \\
\hline 2011.04 & Cree $\leftrightarrow$ Osram & $\begin{array}{l}\text { Inorganic blue LED chip technology, white LEDs and } \\
\text { phosphors, packaging, LED luminaires and lamps, and } \\
\text { electronic LED lighting control system cross-licenses }\end{array}$ \\
\hline
\end{tabular}

Table 2. Ontology definitions

\begin{tabular}{|c|c|c|}
\hline Author & Year & Definition \\
\hline Gruber [8] & 1993 & Ontology has shifted from a focus on formal, explicit specifications of shared concepts. \\
\hline Studer et al. [9] & 1998 & Ontology is a formal, explicit specification of a shared conceptualization. \\
\hline Huang et al. [10] & 2008 & $\begin{array}{l}\text { Describes that the concept of ontology is a model which contain the concepts, links and } \\
\text { relationships in a specific domain that reflects the reality of the world. }\end{array}$ \\
\hline WordNet [11] & 2013 & $\begin{array}{l}\text { A rigorous and exhaustive organization of some knowledge domain that is usually } \\
\text { hierarchical and contains all the relevant entities and their relations. }\end{array}$ \\
\hline
\end{tabular}

According to [12], "Upon finding for the claimant, the court shall award the claimant damages adequate to compensate for the infringement, but in no event less than a reasonable royalty for the use made of the invention by the infringer, together with interest and costs as fixed by the court. When the damages are not found by a jury, the court shall assess them. In either event, the court may increase the damages up to three times the amount found or assessed, ..." Both a lost profits analysis and a reasonable royalty analysis is utilized to calculate patent infringement damages. In Georgia-Pacific Corp. v. United States Plywood Corp., 318 F. Supp. 1116, the court listed fifteen factors considered important for deriving a reasonable royalty [13]. However, the fifteen factor Georgia-Pacific standard has become increasingly difficult for juries to apply in patent lawsuits involving complex high technology products. Therefore, patent litigation potentially results in unpredictably high damage assessments that over compensate patentees [14]. Thus, this research revises [15] heuristic patent valuation approach to estimate reasonable patent royalties for LED patent licensing negotiations.

\section{Ontology}

In the field of computer science, the definition of ontology has shifted from a focus on formal, explicit specifications of shared concepts to an emphasis on determining a rigorous and exhaustive organization of a knowledge domain [8]. WordNet from Princeton University [11] defines ontology as "a rigorous and exhaustive organization of some knowledge domain that is usually hierarchical and contains all the relevant entities and their relations." Ontology provides a unified knowledge base and representation that can be integrated from various sources [16]. We summarize the various definitions of ontology in Table 2.

\section{Patent quality}

[17] states that the value of a patent is best defined as its asset value. Thus, defining patent value considers the patent's effects on costs, prices, and quantities of sales of the patent protected products and the effects on competitors. Patents serve a variety of purposes for patent owners and assignees and the valuation differs based on unique indices of patent characteristics set for different domains [18].

[19] developed specific patent indices and classified patents into categories with general characteristics, quotation or citation indicators, and specification of technologies. [20] adopted twelve patent quality indicators including application length, number of claims, forward citations, technology cycle time, number 
of IPCs, independent claims, foreign citations, science linkage, number of UPCs, patent family, backward citations, and the length of specification. The key indicators are selected based on principal component analysis [20]. These indicators are used as the input parameters to train a back-propagation neural network model which rates the patent quality level as low, medium, or high.

\section{Analytical Procedure for Patent Licensing and Litigation Strategies}

Effective management of a patent portfolio requires a complete assessment of the value of each patent, as well as the costs, risks and rewards of licensing and litigation options [21]. The purpose of this research is to provide LED companies with an effective analysis tool to identify the technology scope and quality levels of their own patents as well as those owned by their competitors. The analytical approach evaluates opportunities for cooperation through cross-licensing or possible enforcement of ownership through litigation. Companies can refer to the past experience of patent licensing cases to create or evaluate IP strategies. In order to identify the technology scope and establish the LED technology ontology, LED technical knowledge is organized into technology categories and sub-categories. First, the major LED companies' patents are searched and core (high quality) patents are identified by applying patent quality analysis. A matrix of IP conducts is organized based on the industry's historical licensing and litigation data. According to the matrix analysis results and the use of the LED ontology, standardized procedures are derived to provide strategic recommendations for LED companies. Figure 1 shows the standardized process for defining patent licensing and litigation used in this research.

\section{LED technical domain ontology}

Ontology defines a specific framework for a particular field of knowledge. [22] refer to ontological engineering as the process of developing an ontology model through iterative steps across the lifecycle of the ontology design. Using the LED industry as our case study, we define a specific framework to generate a standardized architecture and provide references for the analysis of LED patent techniques. Figure 2 shows the process of establishing the LED technical domain ontology.

This research first collects the basic knowledge of LED technologies and places LED techniques into four categories including substrates, epitaxy, illuminants, and packaging, as illustrated in Figure 3. After extracting the key phrases from the four core patent categories, we combine the key phrases of each class to enrich the basic ontology schema originally drafted in Figure 3. Thus, the combined LED techniques and key phrases form an enriched ontology schema that is used to search a specific domain of patents for evaluating licensing and litigation (Figure 4). The framework of the combined LED technique and key phrase ontology is divided into four quadrants with the classifications of techniques and the sub-categories of each technique and their key phrases by quadrant.

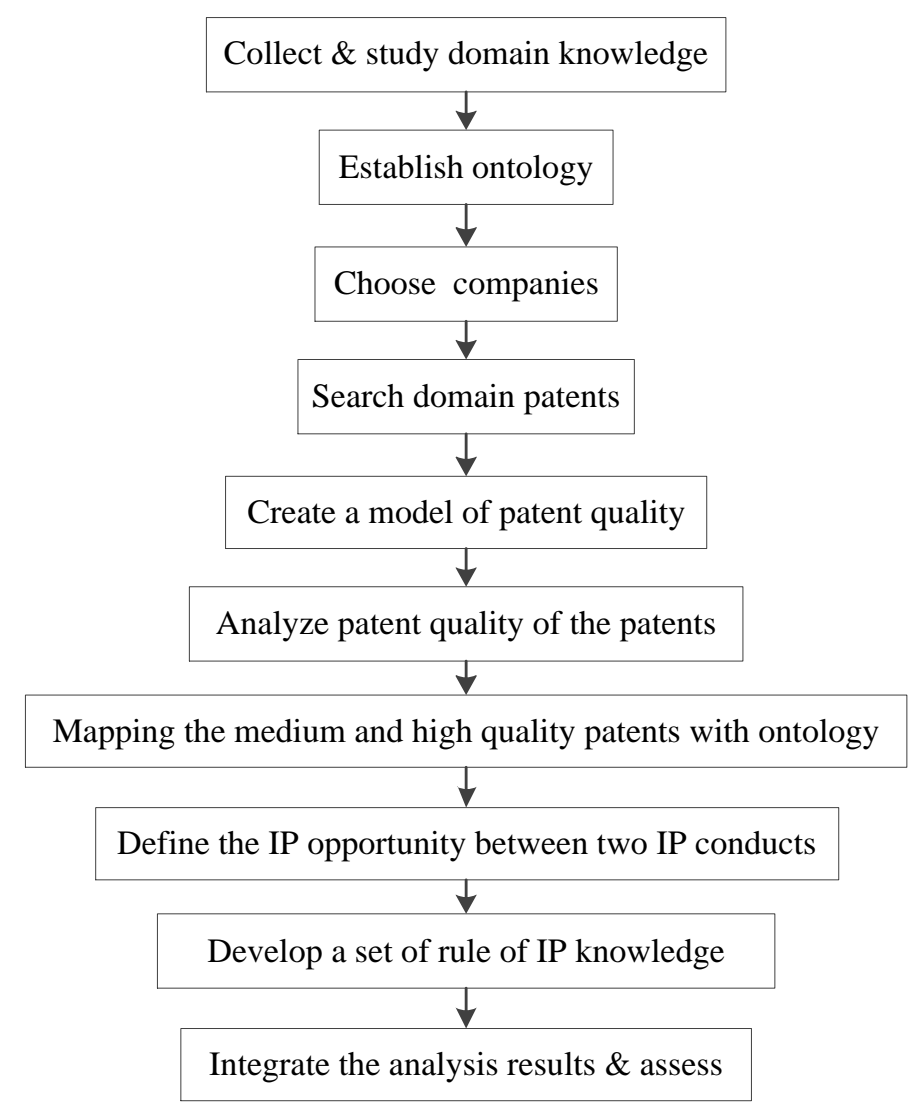

Figure 1. Standardized process for forming patent licensing and litigation strategies.

\section{LED patent quality}

After collecting the domain patent data, the quality of patents is analyzed. This research uses the Intellectual Property Defense-based Support System [23] to generate the report for litigated patent quality. The IPDSS is an online patent analysis system (http://www.wheeljet.com.tw/IPDSS). The system automatically downloads the USPTO patent documents and calculates the predefined patent indicators. After collecting the patent information, the indicators of patent quality derived by IPDSS are selected using principal components analysis (PCA) [24]. The PCA identifies critical quality indicators, including patent 


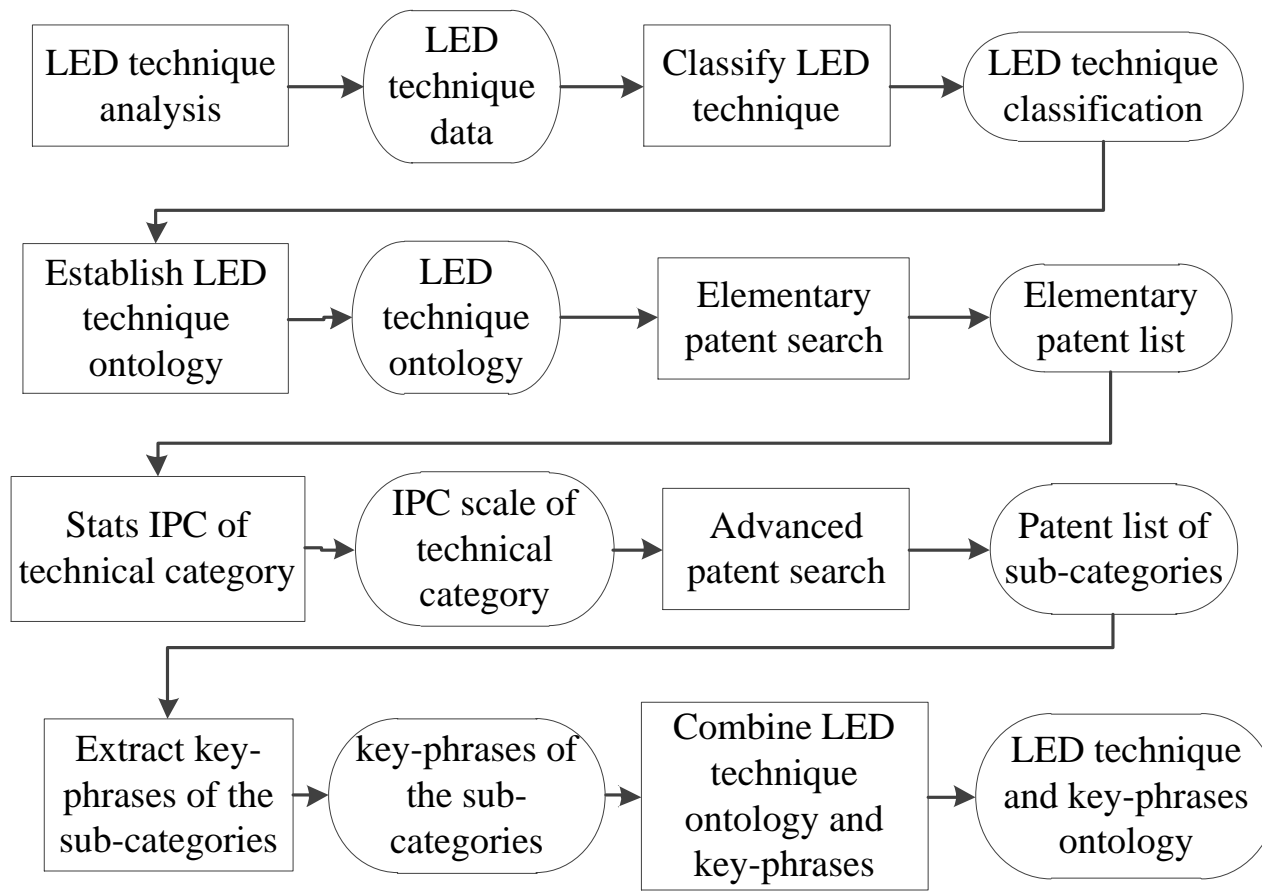

Figure 2. Defining the ontology domain.

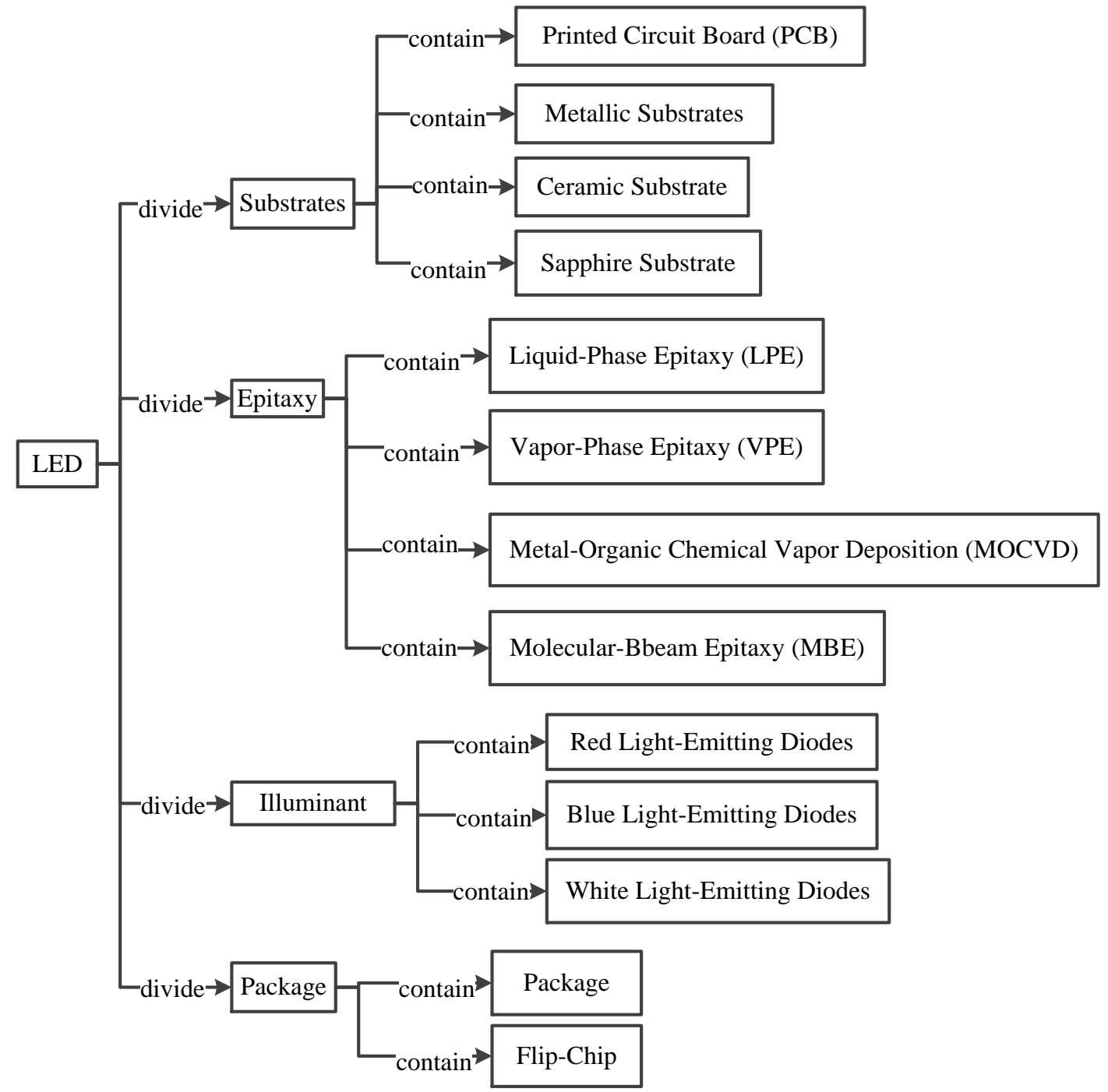

Figure 3. Initial LED ontology schema. 


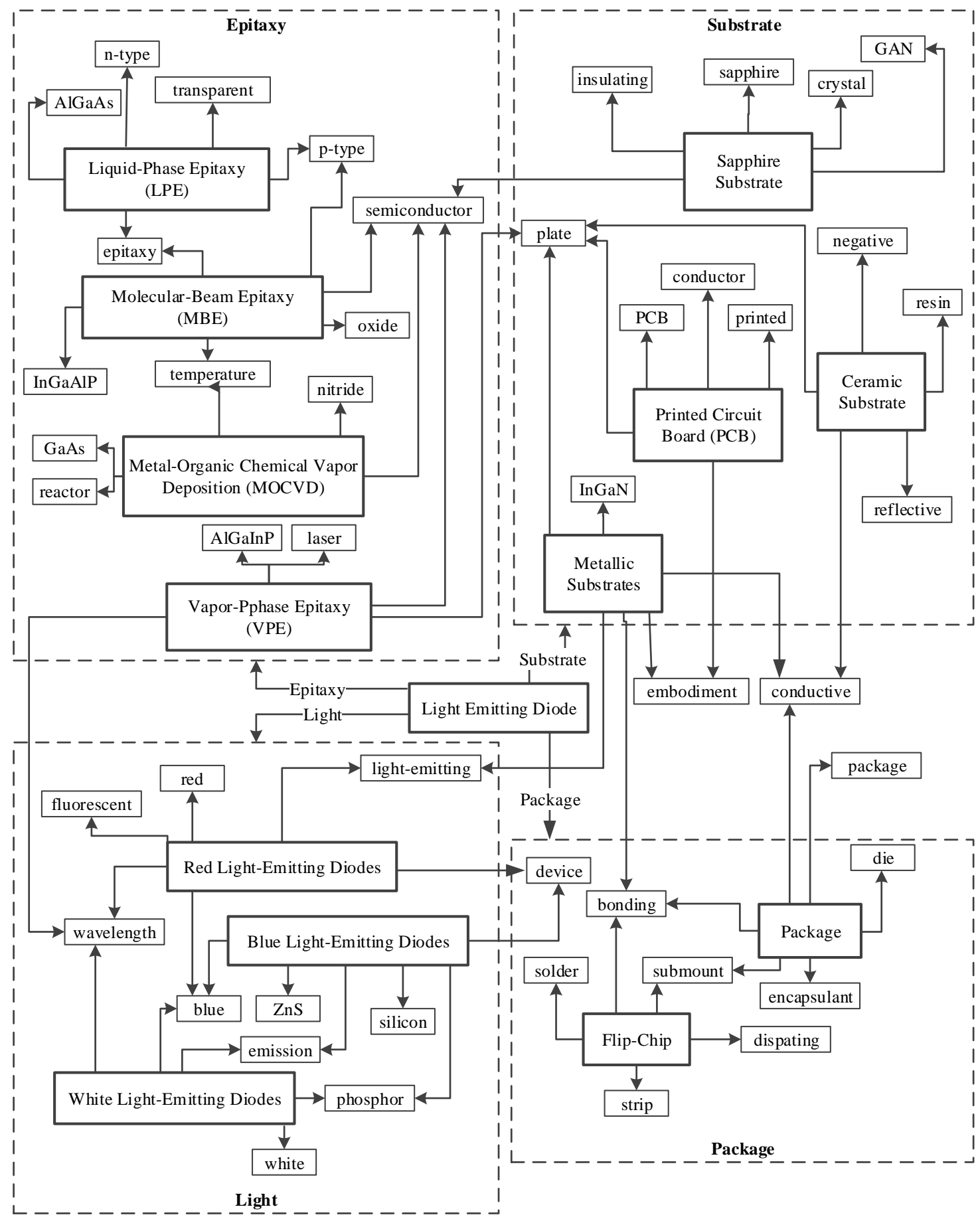

Figure 4. LED techniques and key phrases combine and form an enriched ontology schema with 4 quadrants.

examination time, number of US citations, number of foreign citations, science linkage, backward citations, patent families, technology cycle time, number of claims, number of independent claims, number of IPCs and UPCS. The summation of patent indicator scores for all patents are calculated and used as the quality level measure. In summary, the process uses IPDSS to download and calculate the quality strength of litigated patents. The information from the patent quality report contains patent number, title, assignees, application date, and strength level as shown in Table 3.

\section{Rules of patent licensing and litigation strategies}

According to the analysis of leading LED company historical cases, we find that these companies enhance their competitiveness through cross-licensing or offensive litigation. Thus, a set of heuristic rules are created and flowcharts are defined for incorporating these rules under different circumstances. There are three phases defined in the proposed IP rules. The first phase is to define IP conducts and establish a matrix of these actions. The second phase is to assess the possible 
Table 3. The IPDSS patent quality report example

\begin{tabular}{|c|l|l|c|c|}
\hline \multicolumn{1}{|c|}{ Patent Number } & \multicolumn{1}{c|}{ Assignees } & \multicolumn{1}{|c|}{ Application Date } \\
\hline US6072196 & semiconductor light emitting devices & Ricoh Company, Ltd. (Tokyo, JP) & $1997 / 9 / 4$ & A \\
\hline US6057561 & Optical semiconductor element & $\begin{array}{l}\text { Japan Science and Technology } \\
\text { Corporation(JP) }\end{array}$ & $1998 / 02 / 27$ \\
\hline US5399522 & $\begin{array}{l}\text { Method of growing compound } \\
\text { semiconductor }\end{array}$ & Fujitsu Limited (Kawasaki, JP) & $1993 / 9 / 8$ \\
\hline US5756375 & $\begin{array}{l}\text { Semiconductor growth method with } \\
\text { thickness control }\end{array}$ & $\begin{array}{l}\text { Texas Instruments Incorporated } \\
\text { (Dallas, TX) }\end{array}$ & $1996 / 06 / 14$ \\
\hline US6472690 & $\begin{array}{l}\text { Gallium nitride group compound } \\
\text { semiconductor }\end{array}$ & Toyoda Gosei Co., Ltd. & C \\
\hline
\end{tabular}

pathways of patent licensing and litigation. The third phase is to determine the pathways for negotiating license royalties and litigating patent infringement. Finally, the research develops a patent valuation method to estimate license royalties and claims for damage.

- First phase: Define IP conduct and establish the IP conduct matrix

I. The IP licensing and litigation conduct of LED companies:

This research collated the licensing and litigation cases of each LED company and defines the IP conduct in Table 4.
Table 4. IP conduct code

\begin{tabular}{|c|c|c|}
\hline \multirow{2}{*}{$\begin{array}{c}\text { Conduct } \\
\text { Licensing }\end{array}$} & IP conduct code & IP conduct definition \\
\cline { 2 - 3 } ( ) & A1 & Licensing to others \\
\cline { 2 - 3 } & A2 & Accept the licensing \\
\hline \multirow{2}{*}{$\begin{array}{c}\text { Litigation } \\
\text { (B) }\end{array}$} & A3 & Cross-licensing \\
\cline { 2 - 3 } & B1 & To accuse \\
\hline
\end{tabular}

According to the history of companies studied in the case review, we define conducts which occur with the highest frequency. For example, five cases from Philips show that cross-licensing has the highest frequency with the second highest frequency being patent litigation. Thus, the IP conducts of Philips are shown in Table 5.

Table 5. IP conducts of Philips.

\begin{tabular}{|c|c|c|c|}
\hline Year & Companies & IP activities & IP conduct \\
\hline \multirow[b]{2}{*}{2006} & Philips vs. Toyoda Gosei & Cross-licensing (A3) & \multirow{9}{*}{$\begin{array}{l}\text { Cross-licensing } \\
\text { (A3) }\end{array}$} \\
\hline & \multicolumn{2}{|c|}{$\begin{array}{l}\text { In the cross licensing agreement, Lumileds will allow Toyoda Gosei to use its patents for } \\
\text { high brightness red LEDs and high-power blue LEDs. Likewise, Toyoda Gosei will allow } \\
\text { Lumileds to use its blue LED-related patents }\end{array}$} & \\
\hline \multirow{2}{*}{2007} & Philips vs. Osram & Cross-licensing (A3) & \\
\hline & \multicolumn{2}{|c|}{ The agreement involves the mutual licensing of patents for all inorganic and organic LEDs. } & \\
\hline \multirow[b]{2}{*}{2009} & Philips vs. Epistar & Licensing to the other (A1 \& B1) & \\
\hline & \multicolumn{2}{|c|}{$\begin{array}{l}\text { The two companies have engaged in litigation for over four years, fighting over a patent } \\
\text { claimed by Philips that affected Epistar's production of high-bright and ultra high-bright } \\
\text { red LED chips. Finally, Epistar settled the LED patent dispute out of court with Philips and } \\
\text { signed a licensing agreement. }\end{array}$} & \\
\hline \multirow[b]{2}{*}{2010} & Philips vs. Cree & Cross-licensing (A3) & \\
\hline & \multicolumn{2}{|c|}{$\begin{array}{l}\text { Both parties joined in the field of blue LED chip technology, white LEDs and phosphors } \\
\text { (including remote phosphors), control systems, LED luminaires and lamps as well as LED } \\
\text { backlighting of liquid crystal displays (LCDs) with patents in the Philips LED licensing } \\
\text { program. }\end{array}$} & \\
\hline 2011 & $\begin{array}{c}\text { Philips vs. Seoul } \\
\text { Case: 8:11-cv-00356-AG -RNB }\end{array}$ & Philips to Accuse (B1) & \\
\hline
\end{tabular}


Table 6. Matrix of IP conducts between companies based on their track records.

\begin{tabular}{|c|c|c|c|c|c|}
\hline \multicolumn{1}{|l}{$\begin{array}{l}\text { A conduct of Company } 2 \\
\text { IP conduct of Company 1 }\end{array}$} & Licensing A1 & Licensed A2 & Cross-licensing A3 & Accuse B1 \\
\hline Licensing A1 & A & A & A & B \\
\hline Licensed A2 & A & A & A & B \\
\hline Cross-licensing A3 & A & A & A & B \\
\hline Accuse B1 & B & B & B & B \\
\hline Accused B2 & A & A & A & B & B \\
\hline
\end{tabular}

(A: licensing, B: litigation)

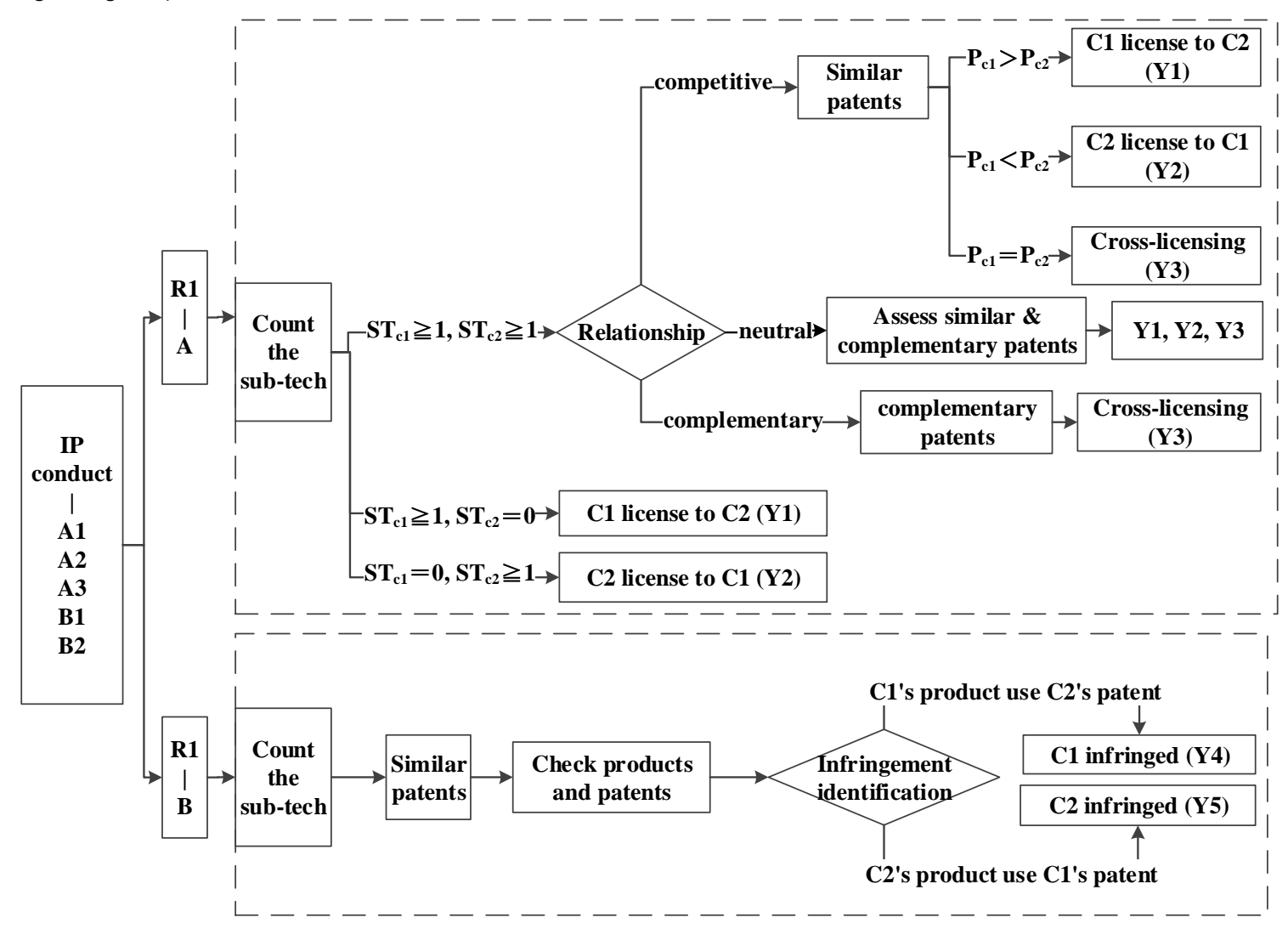

Figure 5. Process of second phase.

II. Establish the IP conduct matrix:

Based on the past IP conduct of each company, Table 6 identifies the types of IP conduct between two companies.

- Second phase: Assess the possible pathways for patent licensing or litigation

Based on the results of the IP conduct matrix, the possible pathways that can be used for patent licensing and litigation are accessed. Figure 5 shows the strategic process of the second phase. Two alternatives are formalized in the second phase: one is licensing $(A)$ and the other is litigation (B).

\section{If $\mathrm{R} 1=\mathrm{A}$ (Licensing)}

I. Analyze the technical scope of company:

After collecting and calculating the strength level of patents owned by a LED manufacturer, patents rated as medium or high quality are selected for further analysis. Next, the technical scope of the company is analyzed. The steps for technical scope analysis follow:

I-1. Extract key-phrases in each patent.

I-2. Compare the key-phrases in each patent using the top five key-phrases of each sub-technique defined in the LED ontology:

If the key-phrases in the patent contain more than four key-phrases of the sub-technique, then place this patent into this sub-technique.

- If the key-phrases in the patent contain less than four key-phrases of the sub-technique, then the patent does not belong to this sub-technique. 
I-3. Define the technical scope of the company: If there are more than three patents in the sub-technique, then the company has this sub-technique.

II. Identify the technique-oriented relationships and choose an optimal licensing strategy. First, compare the sub-techniques of the two companies. There are three scenarios:

II-1. If the items of the sub-techniques of both companies are greater than 1, determine whether their technique-oriented relationship is competitive or complementary based on the following criteria:

If two companies have more sub-techniques in common, then their technical-oriented relationship is competitive. Due to their competitive relationship, there is a high similarity between the patents of the two companies. They may consider jointly licensing these similar patents to the other companies. Different license strategies may be used based on the following criteria:

$\checkmark$ If the items of the sub-technique of company 1 are greater than company 2, company 1 can consider licensing its patents to company 2 (Y1).

$\checkmark$ If the items of the sub-technique of company 1 are less than company 2 , company 2 can consider licensing its patents to company 1 (Y2).

$\checkmark$ If the items of the sub-technique of company 1 are equal to company 2 , the two companies should consider cross-licensing (Y3).

If two companies' identical sub-techniques are equal to their different sub-techniques, then their technical-oriented relationship is neutral. Therefore, assess the similar patents and complementary patents to decide the licensing strategies, including company 1 licensing to company 2 (Y1), company 2 licensing to company 1 (Y2), and cross-licensing (Y3).

- If two companies' identical sub-techniques are less than their different sub-techniques, then their technical-oriented relationship is complementary. Due to their complementary relationship, their patents are not similar. They can consider cross-licensing patents which belong to different sub-techniques (Y3).

II-2. If the items of a particular sub-technique of company 1 are greater than 1 , and the item of the sub-technique of company 2 is 0 , then company 1 should license to company 2 (Y1).
II-3. If the item of a particular sub-technique of company 1 is 0 , and the items of the sub-technique in company 2 are greater than 1 , we say that company 2 should license to company 1 (Y2).

\section{$>\quad$ If $\mathrm{R} 1=\mathrm{B}$ ( Litigation )}

Check the patents and products: If the litigation alternative is based on the results of the IP conduct matrix, check the patents and products further to determine which party will be the plaintiff.

I. If company 1 uses the patents of company 2 (determined by analyzing infringement identification, claim construction, the all elements rule, and the doctrine of equivalents), then company 1 is the infringer (Y4) and company 2 is the plaintiff.

II. If company 2 uses the patents of company 1 (determined by analyzing infringement identification, claim construction, the all elements rule, and the doctrine of equivalents), then company 2 is the infringer (Y5) and company 1 is the plaintiff.

- Third phase: Royalty negotiation and damage claims

In the third phase, patent licensing negotiations and patent litigation processes are considered. This research proposes a modified method of patent valuation to estimate the royalties and the damage remedies for patent infringement.

I. Patent licensing negotiation:

The critical element in licensing negotiations is the amount assessed for royalties. Currently, there are no universal criteria for patent valuation. This research applies the method of patent valuation proposed by [15], a scholar at the North America Intellectual Property Corporation [25]. The resulting patent royalty indices are listed in Table 7. These indices include three classifications including patent quality, patent technique value, and patent portfolio. Patent quality is evaluated using the patent surplus age and the patent quality algorithms in the IPDSS platform (http://www.wheeljet.com.tw/IPDSS). Based on the patent surplus age, the patent can be divided into four phases. The most valuable phase is the growth period (with the patents having a remaining life of 12 to 16 years). There are many competitors during the growth period so the opportunity for patent royalties is high. The second most valuable phase is the mature period (the patent having a remaining life of 5 to 11 years). The mature period contains many products for technology adaptation. Thus, the patent can be easily 
commercialized. The patent quality is calculated in IPDSS based on the quality model of litigated patents. The quality evaluation is derived into levels of normal, good, or excellent.

Patent technical value is evaluated using numbers of patents cited and the number of independent claims. The number of patents cited is a positive indicator where the larger the number of patents cited the greater the value ascribed. The numbers of independent claims represent the legal scope of the patent application. Thus, the independent claim is a negative indicator with the greater number of independent claims decreasing the value. The last classification, the patent portfolio, is evaluated by studying the members of the patent family. The patent family represents the overall structure of the product marketplace. Thus, the members of the patent family are an important indicator for enterprise investment.

Each collected patent uses the proposed method to calculate the index values. The estimated values of patent information are extracted and stored in this research database for determining licensing negotiation strategies and patent royalties.
The following formula (1) is the equation used for patent valuation. The weights for the assessed indices are defined by the domain expert. The weight for patent quality is set at 0.25 , the weight for patent technical value is 0.4 , and the weight for the patent portfolio is 0.35 . The patent value (PV) is calculated using a constant term (0.4), the weights of the assessed indices, the values of the three assessed classifications, and the profit of the to-be licensed company extracted from the annual report. Placing these indices into the formula (2), the patent value is calculated and then used to estimate the licensing royalties. Table 8 shows the domain expert assessment and the historical patent statistics for the patent valuation indexes.

$$
\begin{aligned}
P V= & 0.4 \times\left(W_{0} \sum Q_{i}+W_{T} \sum T_{i}+W_{F} \sum F_{l}\right) \\
& \times(\text { Profit of the be licensed company })^{\prime}
\end{aligned}
$$

where

$$
\begin{aligned}
& W_{Q}+W_{T}+W_{F}=1 \\
& \text { Royalties }=\sum P V_{i}
\end{aligned} .
$$

\begin{tabular}{|c|c|c|}
\hline \multirow[b]{2}{*}{$\begin{array}{l}\text { Patent quality } \\
\qquad\left(\mathrm{W}_{\mathrm{Q}}\right)\end{array}$} & Patent surplus age $\left(\mathbf{Q}_{1}\right)$ & Patent quality $\left(\mathbf{Q}_{2}\right)$ \\
\hline & $\begin{array}{ll}> & 12<\mathrm{Q}_{1}<16 \Rightarrow 1.0 \text { points } \\
> & 5 \leqq \mathrm{Q}_{1} \leqq 12 \Rightarrow 0.75 \text { points } \\
> & \mathrm{Q}_{1} \geqq 16 \Rightarrow 0.5 \text { points } \\
> & \mathrm{Q}_{1}<5 \Rightarrow 0.25 \text { points }\end{array}$ & $\begin{array}{l}>\quad \mathrm{Q}_{2}=\text { excellent } \Rightarrow 0.9 \text { points } \\
>\quad \mathrm{Q}_{2}=\text { good } \Rightarrow 0.6 \text { points } \\
>\quad \mathrm{Q}_{2}=\text { normal } \Rightarrow 0.3 \text { points }\end{array}$ \\
\hline & Numbers of patent cited $\left(T_{1}\right)$ & Numbers of independent claim $\left(\mathrm{T}_{2}\right)$ \\
\hline $\begin{array}{l}\text { Patent technical value } \\
\qquad\left(W_{\mathrm{T}}\right)\end{array}$ & $\begin{array}{ll}> & 90<\mathrm{T}_{1} \Rightarrow 1.0 \text { points } \\
> & 70<\mathrm{T}_{1} \leqq 90 \Rightarrow 0.9 \text { points } \\
> & 50<\mathrm{T}_{1} \leqq 70 \Rightarrow 0.8 \text { points } \\
> & 30<\mathrm{T}_{1} \leqq 50 \Rightarrow 0.65 \text { points } \\
> & 15<\mathrm{T}_{1} \leqq 30 \Rightarrow 0.4 \text { points } \\
> & 5<\mathrm{T}_{1} \leqq 15 \Rightarrow 0.25 \text { points } \\
> & 0 \leqq \mathrm{~T}_{1} \leqq 5 \Rightarrow 0.1 \text { points }\end{array}$ & $\begin{array}{ll}> & 1=\mathrm{T}_{2} \Rightarrow 1.0 \text { points } \\
> & 2=\mathrm{T}_{2} \Rightarrow 0.7 \text { points } \\
> & 3=\mathrm{T}_{2} \Rightarrow 0.3 \text { points } \\
> & 4 \leqq \mathrm{~T}_{2} \Rightarrow 0.1 \text { points }\end{array}$ \\
\hline & \multicolumn{2}{|l|}{ Members of patent family $\left(F_{1}\right)$} \\
\hline $\begin{array}{l}\text { Patent portfolio } \\
\qquad\left(W_{F}\right)\end{array}$ & \multicolumn{2}{|l|}{$\begin{array}{l}8<F_{1} \Rightarrow 1.0 \text { points } \\
6<F_{1} \leqq 8 \Rightarrow 0.85 \text { points } \\
4<F_{1} \leqq 6 \Rightarrow 0.75 \text { points } \\
2<F_{1} \leqq 4 \Rightarrow 0.6 \text { points } \\
0 \leqq F_{1} \leqq 2 \Rightarrow 0.2 \text { points }\end{array}$} \\
\hline
\end{tabular}

Table 7. Patent valuation indexes.

\begin{tabular}{|c|l|l|}
\hline Assess classification (Weight) & Assess classification index & \multicolumn{2}{|c|}{ Code } \\
\hline Patent quality $\left(\mathbf{W}_{\mathbf{Q}}\right)$ & Patent surplus age & $\mathrm{Q}_{1}$ \\
\cline { 2 - 3 } & Patent quality & $\mathrm{Q}_{2}$ \\
\hline Patent technique value $\left(\mathbf{W}_{\mathbf{T}}\right)$ & Numbers of patent cited & $\mathrm{T}_{1}$ \\
\cline { 2 - 3 } & Numbers of independent claims & $\mathrm{T}_{2}$ \\
\hline Patent portfolio $\left(\mathbf{W}_{\mathbf{F}}\right)$ & Members of patent family & $\mathrm{F}_{1}$ \\
\hline
\end{tabular}

Table 8. Patent valuation index descriptions. 
I-1. If R1 $=A$ (Licensing) and R2 $=\mathrm{Y} 1$ (Company 1 licensing to Company 2): According to the results of the second phase (R2), if Company 1 licenses to Company 2, the final step is to estimate royalties. To assess the value of licensing the patents of Company 1 , formula (1) and formula (2) are used to calculate the royalties. If Company 2 can accept the royalties, then they sign a license agreement.

I-2. If $\mathrm{R} 1=\mathrm{A}$ (Licensing) and $\mathrm{R} 2=\mathrm{Y} 2$ (Company 2 license to Company 1): According to the results of the second phase (R2), if Company 2 licenses to Company 1, the final step is to estimate royalties. To assess the value of licensing the patents of Company 2, formula (1) and formula (2) are used to calculate the royalties. If Company 1 can accept the royalties, then they sign a license agreement.

I-3. If $\mathrm{R} 1=A$ (Licensing) and $\mathrm{R} 2=\mathrm{Y} 3$ (Cross-licensing): According to the results of the second phase (R2), if R2 is cross-licensing, the last step is to estimate the royalties of both sides. To evaluate the value of the each licensed patent, use formula (1) and formula (2) to calculate the royalties. If both companies accept the royalties, then they sign a cross-licensing agreement.

II. Patent litigation result

According to case 35 U.S.C. § 284 [8], there are two types of patent infringement damages, i.e., the lost profit calculation and the reasonable royalty calculation. Since most information is not publically available, this research chooses the most reasonable royalty calculation to estimate damages. The Y4 scenario (shown in Figure 5), i.e., Company 1 (C1) being the infringer and Company 2 (C2) being the plaintiff, is used to outline the heuristic process of litigation and damage claims.

II-1. C2 starts to investigate C1's patents and products. If $\mathrm{C} 2$ finds $\mathrm{C} 1$ 's products infringed upon C2's IPs, the damages caused by $\mathrm{C} 1$ are estimated. After being presented with the evidence, C2 can license its IPs to C1 by entering into the licensing process (Y2) or file the lawsuit against C1 (Y4) with potential results of winning the lawsuit, losing the lawsuit, or reconciliation.

II-2. On the other hand, C1 can counter-check the validity of $\mathrm{C} 2$ 's patents in dispute. If $\mathrm{C2}^{\prime} \mathrm{s}$ patents are proved to be invalid, the infringement litigation is a false accusation by C2 and the case is dropped. Otherwise, if C2 has a valid claim, follow the heuristic process II-1 for resolution.

\section{Conclusions}

Five leading LED companies have organized very competitive patent licensing strategies. A complete assessment of the value of each patent including the costs, risks and rewards of licensing and litigation are critical to effective patent management. Since the current fifteen factor Georgia-Pacific standard for determining a reasonable royalty is difficult to apply in high-technology LED patent lawsuits, this research incorporates heuristic knowledge rules and refines three-classification methods for patent valuation of LED technology and derives licensing and litigation strategies for competitive market actions.

Case data are collected from previous LED patent litigation and licensing events and LED domain knowledge is used to build the LED ontology. Key-phrases are extracted from patents using data- and text-mining techniques. Afterwards, patent quality is estimated and medium and high quality patents are selected as possible candidates for licensing. A set of rules for deriving IP strategies and patent evaluation are described to provide LED companies with decision support to evaluate their own patents and develop IP licensing and royalty negotiation strategies. The research allows LED companies to evaluate the advantages and shortcomings of their own patents and IPR holdings and potentially gain competitive advantages during licensing and negotiation.

\section{Acknowledgements}

This research was partially supported by a ROC National Science Council research grant, as well as the Ministry of Education grant for Advanced Manufacturing and Service Management Research at the National Tsing Hua University. Moreover, special thanks are due to Ms. Meng-Chun Kuo, the Director of Intellectual Property Office at Epistar Corporation, for her valuable comments and suggestions.

\section{References}

[1] David, China's led industry over the "minefield" the risk of expansion of listed companies., Chinese Manufacturer directory, 2011, [Online].

Available:

http://www.chinese-manufacturers.org/2011/08/c hinas-led-industry-over-the-minefield-the-risk-of-e xpansion-of-listed-companies/ [Accessed: January 25,2013 ] 
[2] X. Shi, "Patent licensing for technology transfer: An integrated structural model for research," International Journal of Technology Management, vol. 10, no. 7-8, pp. 921-940, 1995. doi: $10.1504 /$ IJTM.1995.025667

[3] C. lo Storto, "A method based on patent analysis for the investigation of technological innovation strategies: The european medical prostheses industry," Technovation, vol. 26, no. 8, pp. 932-942, 2006.

doi: 10.1016/i.technovation.2005.10.005

[4] A. Sarkissian, "Intellectual property rights for developing countries: Lessons from iran," Technovation, vol. 28, no. 11, pp. 786-798, 2008. doi: 10.1016/i.technovation.2008.04.001

[5] H. Hytönen, T. Jarimo, A. Salo, and E. Yli-Juuti, "Markets for standardized technologies: Patent licensing with principle of proportionality," Technovation, vol. 32, no. 9-10, pp. 523-535, 2012. doi: 10.1016/j.technovation.2011.08.002

[6] S. Lee, B. Yoon, and Y. Park, "An approach to discovering new technology opportunities: Keyword-based patent map approach," Technovation, vol. 29, no. 6-7, pp. 481-497, 2009. doi: 10.1016/i.technovation.2008.10.006

[7] Science \& Technology Policy Research and Information Center (STPI), [Online].

Available:

http://cdnet.stpi.narl.org.tw/techroom/pclass/201 0/pclass 10 A243.htm

http://cdnet.stpi.org.tw/techroom/pclass/2011/pcl ass 11 A103.htm [Accessed: November 15, 2012]

[8] T. R. Gruber, "A translation approach to portable ontology specifications," Knowledge Acquisition, vol. 5, no. 2, pp. 199-220, 1993.

doi: $\underline{10.1006 / \mathrm{knac} .1993 .1008}$

[9] R. Studer, V. R. Benjamins, and D. Fensel, "Knowledge engineering: Principles and methods," Data Knowl. Eng., vol. 25, no. 1-2, pp. 161-197, 1998.

doi: $10.1016 / \mathrm{s} 0169-023 \times(97) 00056-6$

[10] C. J. Huang, A. J. C. Trappey, and C. Y. Wu, "Develop a formal ontology engineering methodology for technical knowledge definition in r\&d knowledge management," in 15th ISPE International Conference on Concurrent Engineering (CE 2008), N. Ireland, UK, 2008, pp. 495-502.

doi: $10.1007 / 978-1-84800-972-146$

[11] Wordnet search 3.1, [Online].

Available:

http://wordnetweb.princeton.edu/perl/webwn?s= ontology [Accessed: January 21, 2013]
[12] United states code. Title 35: Patents. Chapter 29: Remedies for infringement of patent, and other actions. Section 284: Damages., [Online].

Available:

http://www.gpo.gov/fdsys/pkg/USCODE-2011-title 35/pdf/USCODE-2011-title35-partIII-chap29-sec28 4.pdf [Accessed: January 21, 2013]

[13] D. Foster, Here are the 15 georgia-pacific factors considered for patent infringement, 2010, [Online]. Available:

http://www.ipvalue-site.com/index.php/2010/09/ 15/here-are-the-15-georgia-pacific-factors-conside red-for-patent-infringement/

[14] C. B. Seaman, "Reconsidering the georgia-pacific standard for reasonable royalty patent damages," BYU Law Review, no. 5, pp. 1661, 2010.

Available: http://ssrn.com/abstract $=1575805$

[15] D. Y. Tan, North America Intellectual Property Co., 2007, [Online].

Available:

http://www.naipo.com/Portals/1/web tw/Knowle dge Center/Application/publish-16.htm [Accessed: January 21, 2013]

[16] S. Taduri, G. T. Lau, K. H. Law, H. Yu, and J. P. Kesan, "Developing an ontology for the u.S. Patent system," in 12th Annual International Digital Government Research Conference: Digital Government Innovation in Challenging Times, College Park, Maryland, 2011. pp. 157-166.

doi: $10.1145 / 2037556.2037579$

[17] M. Reitzig, "Improving patent valuations for management purposes-validating new indicators by analyzing application rationales," Research Policy, vol. 33, no. 6, pp. 939-957, 2004.

doi: 10.1016/j.respol.2004.02.004

[18] S. S. Nair, M. Mathew, and D. Nag, "Dynamics between patent latent variables and patent price," Technovation, vol. 31, no. 12, pp. 648-654, 2011. doi: 10.1016/i.technovation.2011.07.002

[19] M. S. Yuan, C. C. Liang, "The study of development of patent indexes," Journal of Library and Information Science, vol. 35, no. 2, pp. 88-106, 2009.

[20] A. J. C. Trappey, C. V. Trappey, C.-Y. Wu, and C.-W. Lin, "A patent quality analysis for innovative technology and product development," Advanced Engineering Informatics, vol. 26, no. 1, pp. 26-34, 2012. doi: $10.1016 /$ i.aei.2011.06.005

[21] B. C. Haas and C. V. Beckman, "Patent enforcement: Licensing and litigation considerations," Building and enforcing intellectual property value, pp. 68-71, 2008. 
[22] A. J. C. Trappey, C. J. Huang, and C. Y. Wu, "Building a formal ontology engineering methodology for knowledge definition and representation in design knowledge management," Management International Conference, Barcelona, Spain, 2008.

[23] Intellectual property defense-based support system (ipdss), Wheeljet Corporation, [Online]. Available:http://www.wheeljet.com.tw/IPDSS [Accessed: January 21, 2013]
[24] H. F. Kaiser, "The application of electronic computers to factor analysis," Educational and Psychological Measurement, vol. 20, no. 1, pp. 141-151, 1960. doi: $10.1177 / 001316446002000116$

[25] North america intellectual property corporation (naip), [Online].

Available:http://tw.naipo.com/Default.aspx [Accessed: May 28, 2012] 